\title{
熱膨張曲線の測定による天草陶石の耐火度の推定
}

\author{
木村邦夫・立山博・石橋修・陣内和彦 \\ (九州工業技術試験所)
}

\section{Determination of Refractoriness of Amakusa Pottery Stone by Thermal Expansion Curves}

\author{
Kunio KIMURA, Hiroshi TATEYAMA, Osamu ISHIBASHI and Kazuhiko JINNAI \\ $\left(\begin{array}{l}\text { Government Industrial Research Institute, Kyushu } \\ \text { Shuku-machi, Tosu-shi }\end{array}\right)$
}

\begin{abstract}
The correlation between temperature transforming into bloating of a formed sample and nominal temperature equivalent to its refractoriness in the JIS method was positive. This result suggested that refractoriness of Amakusa pottery stone is determined by thermal expansion curves. The various thermal expansion curves were measured under different conditions of milling time of samples, pellet thickness, forming pressure, heating rate and loading. Anomalous expansion due to bloating was observed, and the temperature $\left(T_{5}\right)$ giving a linear expansion coefficient of $5 \times 10^{-4} \mathrm{~cm} / \mathrm{cm} /{ }^{\circ} \mathrm{C}$ was independent of the pellet thickness, forming pressure and loading. The rectification method of $T_{5}$ under the different condition of particle size distribution and heating rate was discussed. The thermal expansion curves of 58 samples were measured under the fixed conditions: milling time: $0.5 \mathrm{~min}$, pellet thickness : $3 \mathrm{~mm}$, forming pressure $: 2500 \mathrm{~kg} / \mathrm{cm}^{2}$, heating rate $: 10^{\circ} \mathrm{C} / \mathrm{min}$ and loading : $10 \mathrm{~g}$. Hence values of $T_{5}$ from the above mentioned thermal expansion curves were calculated. The nominal temperature $\left(T_{s k}\right)$ equivalent to its refractoriness of the same samples was measured by the JIS method. A correlative equation between the rectified temperature $\left(T_{5}{ }^{\prime}\left({ }^{\circ} \mathrm{C}\right)\right)$ from $T_{5}$ using the contents of particles larger than $10 \mu \mathrm{m}$, and $T_{s k}$ $\left({ }^{\circ} \mathrm{C}\right)$ was calculated by the method of least squares as follows,
\end{abstract}

$$
T_{s k}=-1.931 \times 10^{-3} T_{5}{ }^{\prime 2}+6.288 T_{s}{ }^{\prime}-3464 .
$$

The correlation coefficient between $T_{s k}$ calculated by this equation and $T_{s k}$ measured by JIS method was 0.980. The result showed that refractoriness for Amakusa pottery stone can be determined by thermal expansion. [Received September 17, 1985]

Key-words : Refractoriness, Amakusa pottery stone, Thermal expansion, Bloating, Linear expansion coefficient

\section{1. 緒言}

天草陶石は有田・波佐見焼の主原料として用いられて いる.この天草陶石の主要鉱物成分は石英, セリサイト, カオリンからなっている11. また，低品位の陶石中には， 長石, 褐鉄鉱, 菱鉄鉱, 方解石等が不純物として含まれ ている ${ }^{1)}$.これらの天草陶石の耐火度は, 高品位陶石で ほぼ SK 26 であるが，低品位陶石では不純物の含有量 により, SK 26〜12 と変化する.

天草陶石の耐火度は, JIS R 2204 に準じて測定され ている，しかし，JISによると，試料は目開き $297 \mu \mathrm{m}$ のふるいを全通するように粉砕することになっている が, 同一試料でも粉砕方法により, その粒度分布が著し く異なるため, 耐火度も数番異なる結果となる. JIS 法 による耐火度は, 試験コーンの先端が受台に接触すると きに最も近似の変形状態を示す標準ゼーゲルコーンの番 号で示される.しかし, 高温状態での観察は困難であり, また, 標準コーンの精度に著しく左右される，陶土のよ うに試験コーンが曲がり始める温度で膨張するような試 料は, 正確な測定が困難であり, また, 陶土の粒度は, 一般に $100 \mu \mathrm{m}$ 以下であるため, JIS の規定試料粒度と
は全く粒度が異なり, 標準コーンと直接比較できない。

一方，天草陶石を粉砕したのち加圧成形した試料の熱 膨張測定において, 焼結による収縮から発泡による膨張 に移行する温度は, 耐火度と正の相関を示した. そこで, 本報では熱膨張測定により，天草陶石の耐火度を推定す ることを試みた。

\section{2. 実 験}

\section{1. 試料}

熊本県天草郡から種々の天草陶石を 58 試料採取した。 試料粒度, 試料成形法, 熱膨張測定条件等の影響を調べ る実験には，主に表 1 に示す 4 種類の試料を用い，また， 天草陶石の特等石を粉砕して作られている市販の特上陶 土も比較試料として用いた。これらの試料の蛍光 X 線 分析及び熱分析 (Ig. loss の測定) による化学分析值及 び耐火度を表 1 に示す. 測定試料は, 採取陶石を室温乾 燥後, ジョー・クラッシャーにて $1.2 \mathrm{~mm}$ 以下に粗砕し, 更に東洋科学産業製 TI-100 型高速振動試料粉砕機を使 用して, 試料 $2 \mathrm{~g}$ を $10 \mathrm{ml}$ のアルミナ容器中で粉砕した. 試料成形は, 内径 $10 \mathrm{~mm}$ のステンレス製円筒中に一定 
Table 1. Chemical composition (wt\%) and refractoriness (SK) of samples.

\begin{tabular}{c|ccccccccc:c|c}
\hline \hline Name & $\mathrm{SiO}_{2}$ & $\mathrm{TiO}_{2}$ & $\mathrm{Al}_{2} \mathrm{O}_{3}$ & $\mathrm{Fe}_{2} \mathrm{O}_{3}$ & $\mathrm{MgO}$ & $\mathrm{Ca0}$ & $\mathrm{Na}_{2} \mathrm{O}$ & $\mathrm{K}_{2} \mathrm{Ig} .10 \mathrm{ss}$ & Total & Refractoriness \\
\hline UG10 & 79.42 & 0.01 & 14.01 & 0.71 & 0.08 & 0.02 & 0.07 & 1.88 & 4.00 & 100.20 & $27-$ \\
UX01 & 75.76 & 0.01 & 15.54 & 0.40 & 0.12 & 0.07 & 2.37 & 2.39 & 3.39 & 100.05 & $19+$ \\
UG08 & 75.00 & 0.01 & 15.04 & 0.76 & 0.14 & 0.04 & 2.39 & 2.17 & 3.29 & 98.84 & $18+$ \\
KS05 & 75.01 & 0.02 & 14.55 & 0.85 & 0.21 & 0.87 & 0.75 & 3.10 & 4.14 & 99.50 & 17 \\
\hline Tokuj0 & 74.41 & 0.03 & 16.64 & 0.38 & 0.10 & 0.08 & 0.65 & 3.01 & 4.61 & 99.91 & - \\
\hline
\end{tabular}

Table 2. Experimental conditions.

\begin{tabular}{ll|l}
\hline \multicolumn{1}{c|}{ Factor } & \multicolumn{1}{|c}{ Range } \\
\hline Milling time $(\mathrm{min})$ & $0.5^{\star}, 2,8,16$ \\
Forming pressure $\left(\mathrm{kg} / \mathrm{cm}^{2}\right)$ & $1000,1500,2000,2500^{\star}, 3000$ \\
Pellet thickness $(\mathrm{mm})$ & $1.5,3^{\star}, 6$ \\
Heating rate $\quad\left({ }^{\circ} \mathrm{C} / \mathrm{min}\right)$ & $3,5,10^{\star}, 20$ \\
Loading & $(\mathrm{g})$ & $1,2,5,10^{\star}, 20$ \\
\hline
\end{tabular}

*Fixed condition

量の粉砕試料を入れ，加圧成形した。

\section{2 測定装置}

蛍光 $\mathrm{X}$ 線分析及び熱分析 (Ig. loss の測定) は, フィ リップス社製 PW 1400 型蛍光 X 線分析装置及び真空理 工製 DTG-5000 型熱天びんを用いて行った。なお，蛍 光 $\mathrm{X}$ 線分析による化学分析值は, 34 個の天草陶石試料 の湿式分析結果を基にした検量線により求めた.

粒度分布は，七イシン企業製 SKN-500 型光透過式粒 度分布測定器を用いて測定した。

熱膨張は, 真空理工製 TM-1500 型熱機械試験機を用 い，室温～発泡開始温度より約 $50^{\circ} \mathrm{C}$ 上昇した温度間を 測定した.アルミナ台とアルミナ押棒への融着を防止す るため, 成形試料は外径 $13 \mathrm{~mm}$, 厚さ $0.03 \mathrm{~mm}$ の白金 はくで狭んだ. 熱電対先端は, 白金はくに接触させた。 なお，測定值は，三栄測器製 7 V 11 型データアクイジ ションコントローラーを介して, 日立家電製 MB-6892

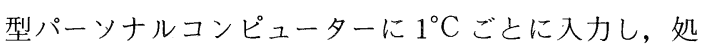
理した。

\section{3 実験条件}

$1.2 \mathrm{~mm}$ 以下に粗砕した武料の振動粉砕機による粉砕 時間 (試料の粒度分布), 成形圧力, 成形試料厚さ, 熱 膨張測定時の昇温速度及び荷重等を変化させた。各実験 条件及び各要因の影響について調べたときの他要因の固 定値を表 2 に示す.

\section{3. 結果と考察}

\section{1 発泡による膨張と耐火度との関係}

一例として, 表 1 に示す 4 種類の天草陶石を $1.2 \mathrm{~mm}$ 以下に粗砕したのち，30 秒間粉砕した試料と市販の特 上陶土の熱膨張測定結果を図 1 に示す。なお，熱膨張測 定における条件は, 固定值とした. 図 1 によると, すべ ての試料において, 熱膨張曲線はわずかに膨張しながら, 石英の $\alpha-\beta$ 転移を経て, $900^{\circ} \mathrm{C}$ 付近から焼結による収縮 が始まり，その後発泡による膨張が見られる．上記過程

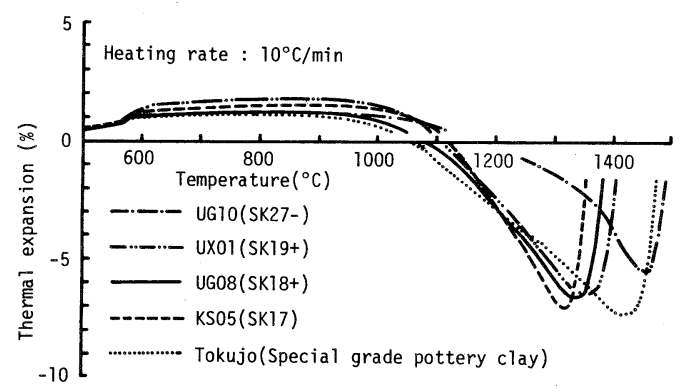

Fig. 1. Thermal expansion curves of samples above $500^{\circ} \mathrm{C}$.

は, ほとんどの天草陶石に見られる現象である ${ }^{3), 4\}}$.また, その発泡による膨張が始まる温度と表 1 の耐火度とは, 正の相関を示している．このことから，発泡による膨張 が始まる温度から耐火度の推定が可能であると考えられ る. しかし，粒度分布の異なる試料，あるいは熱膨張の 測定条件が異なる場合は，同一試料でも発泡による膨張 が始まる温度が変化することが予想される，そこで，各 条件が変化したときの影響について調べた。

\section{2 試験粒度の影響}

表 1 に示す 4 種類の陶石を $1.2 \mathrm{~mm}$ 以下に粗砕したの ち, 振動粉砕機による粉砕時間を変化させて試料を作製 した. 一例として, UG 08 試料の粒度分布を図 2 に示す. 他 3 種類の試料の粒度分布も図 2 とほぼ同様であった。 熱膨張測定結果を図 3 に示す。なお，熱膨張測定におけ る他の要因は, 固定条件とした。

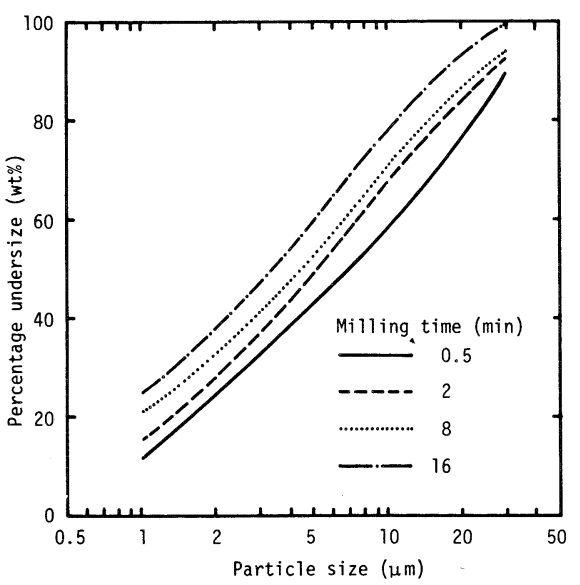

Fig. 2. Particle size distribution of UG08 sample prepared with different milling time. 


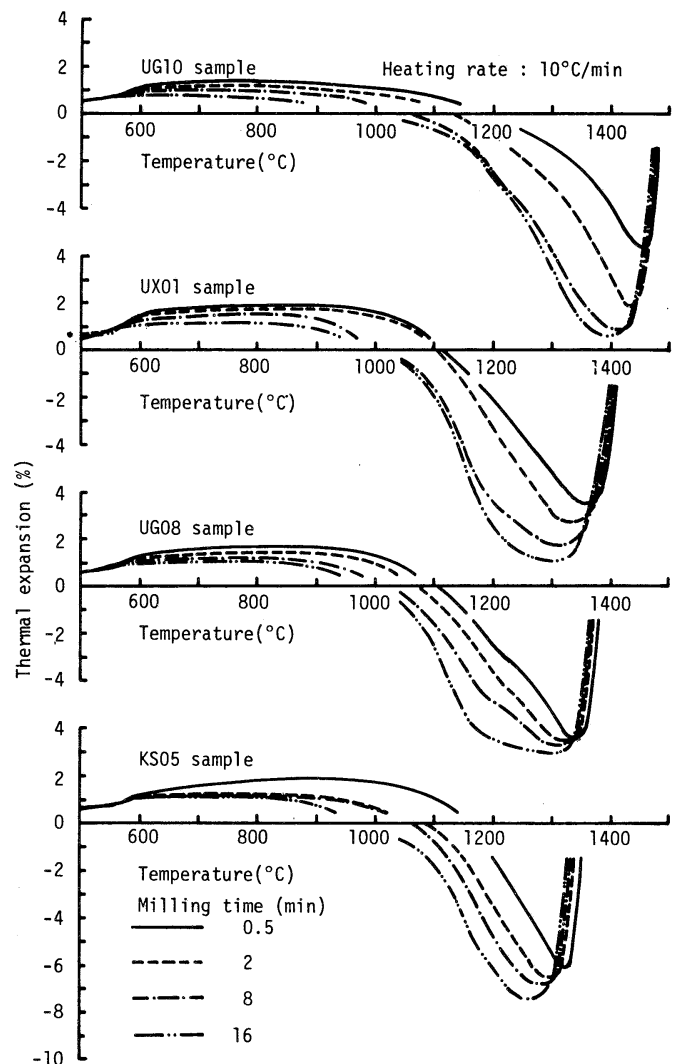

Fig. 3. Thermal expansion curves of samples with different milling time.

図 2 に示すように，粉砕時間を変化させた試料は，粉 砕時間が長くなるほど，全粒度範囲が微粒側に移動して いる.なお， $50 \mathrm{wt} \%$ 径は，30 秒間粉砕試料で $6.5 \mu \mathrm{m}$, 16 分間粉砕試料で $3.5 \mu \mathrm{m}$ であった。また，図 3 による と, 粉砕時間が長い試料ほよ゙，収縮開始温度及び発泡開 始温度が低く，焼結による収縮が大きくなる傾向を示し ている．また，発泡開始温度付近の曲線もなだらかにな り，発泡開始温度の決定が困難となった。なお，30 秒 間粉砕試料の発泡開始温度と 16 分間粉砕試料の発泡開 始温度の差は, $44^{\circ} \sim 63^{\circ} \mathrm{C}$ であった。

陶石に含まれる石英は，粘土鉱物に比べて硬度が高い ため, 陶石粉砕物の粗粒部は石英が多く, 微粒部は粘土 鉱物が多くなる。また，長時間粉砕試料は，石英に富む 粗粒部の含有量が 30 秒 間粉砕試料に比べ少なくなる. 一方, 天草陶石を原料とした磁器の薄片を見ると, 残留 する粗粒部の石英とガラス化した部分が観察される ${ }^{5)}$. これらのことから，粉砕時間が長い試料の焼結並びに溶 融物の生成は, 30 秒間粉砕試料に比べ低温度で起こっ たものと考えられる.

しかし，4 種類の試料とも，発泡開始温度以上におけ る熱膨張曲線は粉砕時間が変化してもほぼ重なってい る. そこで，発泡開始温度以上における熱膨張係数が 5 $\times 10^{-4}$ 及び $10 \times 10^{-4} \mathrm{~cm} / \mathrm{cm} /{ }^{\circ} \mathrm{C}$ になる温度（ $T_{5}$ 及び $T_{10}$ ）を算出した. 30 秒間粉砕試料の $T_{5}$ と 16 分間粉砕 試料の $T_{5}$ の差は, $23^{\circ} \sim 33^{\circ} \mathrm{C}$ であった. また, $T_{10}$.の差は, $T_{5}$ の差とほぼ同じであった。発泡開始温度の差に比べ, 約半分になった。しかし，この温度差は耐火度の推定に 対して無視できない值である，そこで，更に粗粒部の含 有量により $T_{5}$ の值を補正することを試みた。なお，試 料によっては発泡による膨張が小さく $T_{10}$ が得られない こともあるため， $T_{5}$ の值を用いた。

粉砕時間を変化させた試料の $10 ， 20 ， 30 \mu \mathrm{m}$ 以上の 粒子の含有量と $T_{5}$ の值との関係を図 4 に示す。図から, 4 種類の試料の傾向がよく似ているので，変化範囲が広 い $10 \mu \mathrm{m}$ 以上の粒子の含有量で補正が可能と考えられ る.

一般に，陶土試料は， $10 \mu \mathrm{m}$ 以上の粒子が約 $40 \mathrm{wt} \%$ 含まれている ${ }^{6)}$.このことから，10 $\mu \mathrm{m}$ 以上の粒子の含 有量が $40 \mathrm{wt} \%$ を基準值として，4 種類の陶石の平均 2 次曲線を用いて $T_{5}$ の補正式を算出し，次の（1）式を 得た.

$$
T_{5}{ }^{\prime}=T_{5}-0.0203 W_{10}{ }^{2}+0.084 W_{10}+29.12 \text { (1) }
$$

ただ， $T_{5}^{\prime}$ は， $10 \mu \mathrm{m}$ 以上の粒子の含有量が $40 \mathrm{wt} \%$ のとき $T_{5}$ の值 $\left({ }^{\circ} \mathrm{C}\right), W_{10}$ は $T_{5}$ を測定した試料の 10 $\mu \mathrm{m}$ 以上の粒子の含有量 $(\mathrm{wt} \%)$ を示す。

図 4 で示したように，10 $\mu \mathrm{m}$ 以上の粒子の含有量は, 30 秒間粉砕試料が平均的な陶土の $40 \mathrm{wt} \%$ に近い。そ こで，陶石試料の粉砕時間の固定值は，30 秒間とした。

\section{3 試料成形法の影響}

試料成形法に関しては，3.2 節の 4 種類の陶石試料に 加え, 表 1 に示した特上陶土も用いて成形圧力と成形体 厚さを変えて熱膨張の測定を行った．成形圧力を変化さ せた場合は, 成形圧力の増加とともに，焼結に伴う収縮 は，わずかに大きくなる傾向が認められた。 また，固定 值の $2500 \mathrm{~kg} / \mathrm{cm}^{2}$ が $1000 \mathrm{~kg} / \mathrm{cm}^{2}$ になると $T_{5}$ は $6^{\circ} \mathrm{C}$ 上

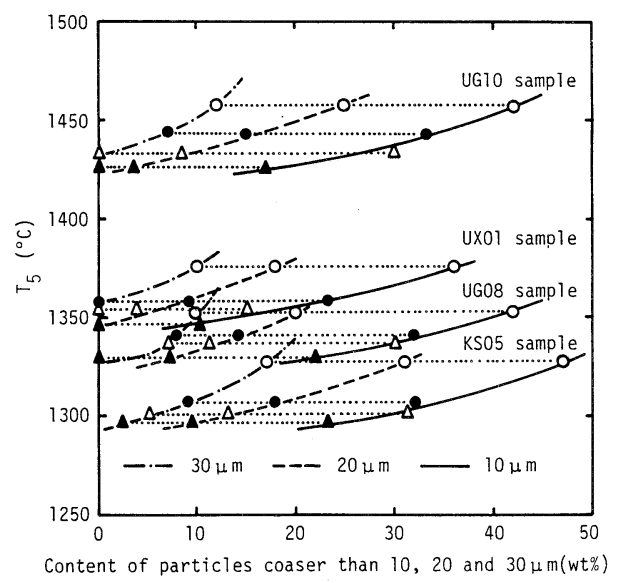

Fig.4. Effect of particle size of samples on $T_{5}$. Milling time $(\min ) \quad \bigcirc: 0.5, \bigcirc: 2, \Delta: 8, \boldsymbol{\Delta}: 16$ 
昇し，逆に $3000 \mathrm{~kg} / \mathrm{cm}^{2}$ になると $T_{5}$ は $2^{\circ} \mathrm{C}$ 降下する結 果が得られた。したがってこの温度差は小さく, 1000〜 $3000 \mathrm{~kg} / \mathrm{cm}^{2}$ の間の成形圧力では補正は必要ないと考え られる.

一方, 試料厚さを変化させた場合は, 焼結に伴う収縮 の割合は，ほとんど変化しなかった。また，固定条件の $3 \mathrm{~mm}$ を $1.5 \mathrm{~mm}$ あるいは $6 \mathrm{~mm}$ に変化させても， $T_{5}$ は ほぼ一定であった。このことから，試料厚さによる補正 は, 全く必要ないと考えられる。

なお, 成形圧力が $2500 \mathrm{~kg} / \mathrm{cm}^{2}$, 成形後の試料厚さが $3 \mathrm{~mm}$ の固定值は，成形試料の強度が保たれ，かつ取り 扱いが容易な成形体が得られる值である。

\section{4 熱膨張測定条件の影響}

3.3 節と同様に, 5 種類の試料を用いて, 昇温速度と 荷重とを変化させて熱膨張の測定を行った. 荷重を変化 させた場合は, 荷重増加とともに, 焼結に伴う収縮は, わずかに大きくなる傾向が認められた。また，固定值の $10 \mathrm{~g}$ が $20 \mathrm{~g}$ になると $T_{5}$ は $2^{\circ} \mathrm{C}$ 上昇し, 逆に $1 \mathrm{~g}$ になる と $2^{\circ} \mathrm{C}$ 下降する結果が得られた。この温度差は小さく, 荷重による補正は，全く必要ないと考えられる。

昇温速度を変化させた場合, 昇温速度が大きくなるほ ぞ，収縮開始温度，発泡開始温度が高くなり，また，焼 結による収縮が小さくなる傾向を示した。しかし，図 3 に比べ, 熱膨張曲線の形状は, 同一試料ではほぼ近似で あった．これは，溶融物の生成並びに石英粒子の溶融物 への溶解が, 同一試料でも昇温速度が大きいほど遅いこ とを示していると考えられる.

次に, 昇温速度と $T_{5}$ の值との関係を図 5 に示す. 図 によると, 昇温速度 (対数目盛り) と $T_{5}$ とは直線関 係にあり， 5 種類の試料のこう配はほぼ一定である。こ のことから, 昇温速度が $10^{\circ} \mathrm{C} / \mathrm{min}$ を基準値として, 5 種類の試料の平均こう配を用いて $T_{5}$ の補正式を算出 し, 次の $(2)$ 式を得た。

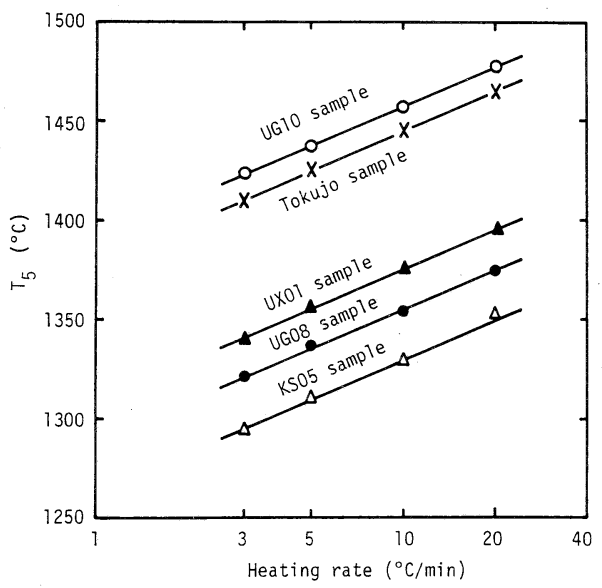

Fig. 5. Effect of heating rate on $T_{5}$.

$$
T_{5}^{\prime \prime}=T_{5}+66.96\left(1-\log H_{\mathrm{r}}\right)
$$

ただし， $T_{5}^{\prime \prime}$ は $10^{\circ} \mathrm{C} / \mathrm{min}$ の昇温速度で測定したときの $T_{5}$ の值 $\left({ }^{\circ} \mathrm{C}\right), H_{\mathrm{r}}$ は $T_{5}$ を測定したときの昇温速度 $\left({ }^{\circ} \mathrm{C} / \mathrm{min}\right)$ を示す.

3.3 節までの結果とは異なり, 昇温速度の変化に伴い $T_{5}$ は大きく変化するため, 昇温速度が変化した場合は ( 2 ) 式による $T_{5}$ の補正が不可欠であると考えられる.

\section{$3.5 T_{5}$ における耐火度の推定}

以上の実験結果から，粒度分布が大きく異なる場合を 除いて， $T_{5}$ に最も強く影響を及ぼす要因は昇温速度で あることが明らかになった。一定条件で測定することが 必要であるが, 特に昇温速度に関しては, 正確な制御が 必要であると思われる.

採取した 58 個の試料を $1.2 \mathrm{~mm}$ 以下に粗砕したのち, 30 秒間粉砕した。なお， $10 \mu \mathrm{m}$ 以上の粒子の含有量の 平均值は $44.2 \mathrm{wt} \%$ であり，その標準偏差は $4.3 \mathrm{wt} \%$ であった。各試料について表 2 の固定值で熱膨張の測定 を行い $T_{5}$ を得た。一方, JIS R 2204 による耐火度の測 定も行い, その SK 值に対応するゼーゲルコーンの溶倒 温度 $\left(T_{\mathrm{sk}}\right)$ を得た。なお, $T_{\mathrm{sk}}$ は耐火度を $2 \sim 3$ 回測定し, その溶倒温度の平均值とした. 両者の関係を図 6 に示す。

両者の 2 次相関式を最小二乗法により求め, その相関 式を用いた推定值と，JIS 法による耐火度の測定值から 得られた溶倒温度との相関係数を計算し，0.972 の値を 得た. 更に, 58 試料の粒度分布測定值から得られる 10 $\mu \mathrm{m}$ 以上の粒子の含有量を用い， $T_{5}$ を $(1)$ 式により補 正した。 その補正值と $T_{\mathrm{sk}}$ との 2 次相関式を最小二乗 法により求め, 次の $(3)$ 式を得た。

$$
T_{\mathrm{sk}}=-1.931 \times 10^{-3} T_{5}{ }^{2}+6.288 T_{5}^{\prime}-3464(3)
$$

(3) 式を用いた推定值と, JIS 法による耐火度の測定 值から得られた溶倒温度との関係を図 7 に示す. 推定值

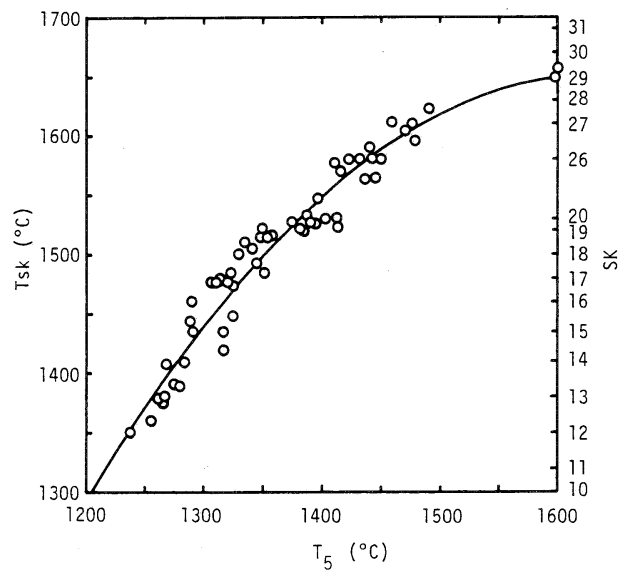

Fig. 6. Relation between $T_{5}$ and $T_{\text {sk }}$.

$T_{5}$ : Temperature at linear expansion coefficient of $5 \times$ $10^{-4} \mathrm{~cm} / \mathrm{cm} /{ }^{\circ} \mathrm{C}$ of bloating in thermal expansion curve, $T_{\text {sk }}$ : Nominal temperature equivalent of its refractoriness under the JIS method 


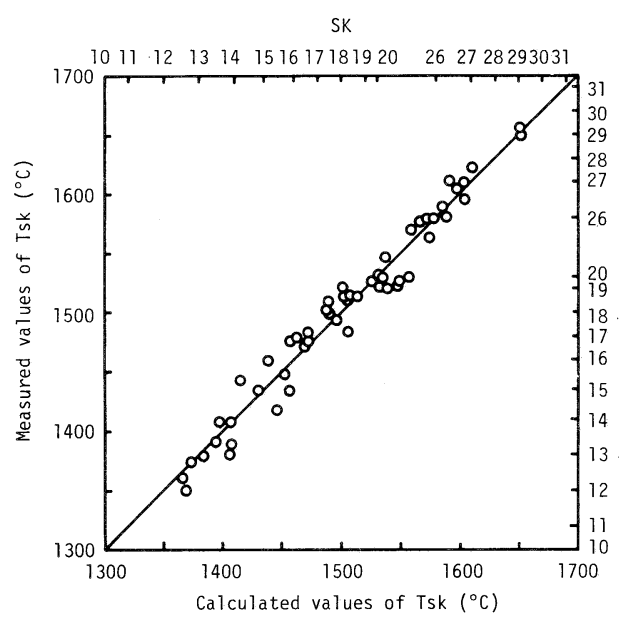

Fig. 7. Relation between $T_{\mathrm{sk}}$ calculated by Eq. ( 1 ) and $T_{\mathrm{sk}}$ measured by JIS method.

と実測值との相関係数は 0.980 であった。粉砕時間が同 じ 30 秒間でも，天草陶石の種類により被粉砕性が異な るため，粒度分布が一定でない，そのため，粒度補正す ることにより粒度分布の影響がなくなり，相関係数の值 が大きくなったものと考えられる．このことから，10 $\mu \mathrm{m}$ 以上の粒子の含有量を測定した試料を用いると，よ り正確な耐火度の推定が可能となることが明らかになっ た。

しかし，（1）式によると, $10 \mu \mathrm{m}$ 以上の粒子の含有 量が $40 \pm 5 \mathrm{wt} \%$ の範囲の試料の場合, $T_{5}{ }^{\prime}$ の值は $T_{5} \pm$ $8^{\circ} \mathrm{C}$ となる.この值は, 温度範囲が狭い SK $19 \sim \mathrm{SK} 20$ の間以外では，耐火度の推定に対しては，ほとんど影響 しないと考えられる．前記したように，30 秒間粉砕試 料の $10 \mu \mathrm{m}$ 以上の粒子の含有量は, ほぼ基準值 $(40 \mathrm{wt} \%)$ に等しくなる。また，（1）式による補正をしない場合 の相関係数の值は大きい.これらのことから，実用上は 同一条件で粉砕, 成形, 熱膨張の測定を行い, 得られる $T_{5}$ を（3）式の $T_{5}{ }^{\prime}$ に代入することにより, 耐火度が 推定できると考えられる.

\section{4. 結言}

天草陶石の粉砕物を円盤状に加圧成形した試料の熱膨 張測定により, 天草陶石の耐火度を推定することを試み， 下記の結果を得た。
（1）同一条件で粉砕，成形，熱膨張測定したときの 焼結による収縮から発泡による膨張に移行する温度と耐 火度とは正の相関を示した。

（2）同一試料でも，粒度が小さくなると，収縮開始 温度及び発泡開始温度は低くなり, 焼結に伴う収縮は大 きく, 発泡開始温度付近の熱膨張曲線もなだらかになる 傾向を示した。

(3) 熱膨張曲線中の発泡による膨張の線膨張係数 が， $5 \times 10^{-4} \mathrm{~cm} / \mathrm{cm} /{ }^{\circ} \mathrm{C}$ になる温度 $\left(T_{5}\right)$ で比較したと ころ，粒度の影響が少なくなった。

（4）上記の $T_{5}$ の值に対して, 実験条件範囲内では, 昇温速度の変化が最も大きな影響を与えた. $10 \mu \mathrm{m}$ 以上 の粒子の含有量が基準值とした $40 \mathrm{wt} \%$ と異なる場合, 及び昇温速度が異なる場合の $T_{5}$ の值の補正式 $(1)$ 式 及び ( 2 ) 式が得られた.

（5）採取した種々の天草陶石 58 試料を用いて，同 一条件で粉砕, 成形, 熱膨張測定し, 得られた $T_{5}$ を 10 $\mu \mathrm{m}$ 以上の粒子の含有量を用いて補正した温度 $\left(T_{5}{ }^{\prime}\right)$ と耐火度の実測値から得られた溶倒温度 $\left(T_{\mathrm{sk}}\right)$ との間 に下記の 2 次相関式が得られた。

$$
T_{\mathrm{sk}}=-1.931 \times 10^{-3} T_{5}{ }^{2}-6.288 T_{5}{ }^{\prime}-3464
$$

上式を用いた推定值と実測值との相関係数は，0.980で あり, 熱膨張の測定から耐火度の推定が可能と思われる.

（6）粒度による補正をしない場合の相関係数は, 0.972 であった。この值も大きく, 実用上は, 同一条件 で粉砕, 成形, 熱膨張の測定を行うことにより, 耐火度 の推定が可能と思われる.

謝辞 本研究を行うに当たり, 耐火度の測定は, 天草陶 石鉱業協同組合，佐賀県窯業試験場，熊本県工業試験場の方々 にお願いした。これらの方々に対して心より謝意を表します.

\section{文献}

1）富樫幸雄, 地調月報, 25，491-508（1974）。

2）林 文男, 永田正典, セラミックス, 14, 333-38 (1974).

3）児玉 久, 星野義昭, “粘土科学の進歩 ( 4 )”, 技報堂 (1953) p. 291-300.

4) K. Hamano, H. Takeshi, Z. Nakagawa and M. Hasegawa, Report of Research Laboratory of Engineering Materials, Tokyo Institute of Technology, 7, 71-85 (1982).

5）浜野健也, “天草陶石の特徴之業界診断報告に関連して”, 熊本県 (1974) p. 1-24.

6）永田正典, 本田悠紀雄, 林 文男, 古江俊夫, 原田 爾, 森 繁之, 松岡良三, 熊本県工業試験場研究報告, 21 , 1-9 (1983). 